\title{
APLIKASI TEKNOLOGI MIKROBUBBLE PADA PETANI IKAN NILA DI DESA BAYAN
}

\author{
Andre Rachmat Scabra*1, Muhammad Marzuki², Bagus Dwi Hari Setyono², Nanda \\ Dininiarti ${ }^{1}$, Laily Fitriani Mulyani ${ }^{1}$ \\ ${ }^{1}$ Program Studi Budidaya Perairan Universitas Mataram, ${ }^{2}$ Program vokasi unram di \\ kabupaten lombok utara \\ ${ }^{1} J a l a n$ pendidikan nomor 37 Kota Mataram
}

Alamat Korespondensi : andrescabra@unram.ac.id

(Tanggal Submission: 3 Desember 2020, Tanggal Accepted : 2 Februari 2021)

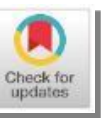

\begin{abstract}
Keyword : Abstrak :
budidaya ikan

nila, desa Desa Bayan Kabupaten Lombok Utara memiliki potensi sumberdaya air dengan kuantitas yang bayan, cukup memadai. Berdasarkan pemantauaan saat melakukan survey awal pada awal bulan mikrobubble, februari 2020, dari segi kualitas, kondisi air yang digunakan untuk kegiatan budidaya ikan kabupaten belum memenuhi kaidah standart sertifikasi Cara Budidaya Ikan yang Baik (CBIB). Kegiatan lombok utara pengabdian kepada masyarakat ini bertujuan untuk meningkatkan produktifitas lahan budidaya ikan di Desa Bayan dengan cara melakukan perbaikan kualitas air, yaitu meningkatkan kandungan oksigen terlarut, melalui aplikasi teknologi microbubble. Kegiatan ini dileksanakan melalaui beberapa kegiatan, antara lain dengan melakukan sosialisai tentang sertifikasi Cara Budidaya Ikan yang Baik (CBIB) yang meliputi semua aspek kompleks yang menjadi permasalahan pada kelompok pembudidaya, yaitu manajemen kualitas air, tata kelola letak pembangunan kolam budidaya, SDM pengelola kolam budidaya, pemberian pakan dan obat ikan, panen, transportasi ikan, dll. Pada kelompok tersebut juga diujicobakan teknologi mikrobubble untuk meningkatkan kadar oksigen pada kolam budidaya masyarakat. Micro bubble pada media budidaya ikan dapat dihasilkan dengan beberapa metoda dengan karakteristik yang berbeda-beda. Metoda tersebut antara lain dengan elektrolityc microbubble generator, porous plate (PP), ventury tube type bubble generator, dan spherical body in a flowing water tube. Mikrobubble yang diujicobakan pada kegiatan ini adalah mikrobubble bertipe ventury tube. Aplikasi tekhnologi ini dapat menghasilkan produktifitas ikan yang lebih tinggi dibandingkan dengan pemeliharaan ikan yang tidak menerapkan tekhnologi ini.
\end{abstract}

Panduan Sitasi (APPA $7^{\text {th }}$ edition) :

Scabra, A.R., Marzuki, M., Setyono, B.D.H., Diniarti, N., \& Mulyani, L.F. (2021). Aplikasi Tekhnologi Mikrobubble Pada Petani Ikan di Desa Bayan. Jurnal Pengabdian Perikanan Indonesia, 1 (1), 36-43. http://doi.org/ 10.29303/jppi.v1i1.56 


\section{PENDAHULUAN}

Desa Bayan adalah salah satu desa pada Kecamatan Bayan, Kabupaten Lombok Utara, Provinsi Nusa Tenggara Barat. Desa ini memiliki potensi sumberdaya alam yang cukup baik pada sektor pertanian, perikanan, dan perkebunan. Menurut Anonimous (2014) pada website resmi pemerintahan Kabupaten Lombok Utara, Desa Bayan memiliki Luas wilayah 1.824,50 ha. Luas area persawahan sejumlah 1305,00 ha dan luas tanah perkebunan sejumlah 340 ha. Sistem pengairan area persawahan dan perkebunan bersumber dari sistem irigasi $1 / 2$ tekhnis yang merupakan hasil bentukan perangkat desa setempat. Potensi luas lahan tersebut telah sebagian termanfaatkan oleh masyarakat namun masih memerlukan usaha pengembangan (optimalisasi lahan).

Kuantitas sumberdaya air pada Desa Bayan cukup memadai sehingga kegiatan perikanan dan beberapa sektor terkait dapat berjalan. Beberapa kelompok masyarakat yang tergabung sebagai kelompok pembudidaya ikan pun terbentuk berdasarkan kondisi potensi pada wilayah ini. Jenis kegiatan pembudidayaan ikan yang dilakukan oleh masyarakat Desa Bayan antara lain budidaya ikan Nila GIFT, yang dipelopori oleh kelompok pembudidaya ikan yang bernama "Tani Jago", Desa Bayan Kabupaten Lombok Utara. Kegiatan pembudidayaan ikan tersebut telah berlangsung cukup lama, yaitu sejak tahun 2017. Eksistensi kelompok pembudidaya ikan ini menjadi indikasi bahwa usaha ini memiliki prospek yang cukup bagus. Ikan hasil budidaya yang diproduksi oleh kelompok masyarakat selalu habis terjual pada pasaran yang masih meliputi daerah lokal, yaitu sekitar wilayah Kabupaten Lombok Utara.

Berdasarkan pemantauaan saat melakukan survey awal pada awal bulan februari 2020, kondisi air yang digunakan untuk kegiatan budidaya ikan belum memenuhi kaidah standart sertifikasi Cara Budidaya Ikan yang Baik (CBIB). Indikator yang menjadi penilaian adalah nilai kekeruhan yang cukup tinggi. Hal tersebut kemungkinan terjadi karena sumber air yang digunakan adalah sumber air irigasi yang juga digunakan untuk keperluan lahan pertanian. Boyd (1982) menyatakan bahwa nilai kekeruhan pada media budidaya ikan dapat berpengaruh terhadap beberapa faktor kualitas air lainnya. Salah satu parameter yang berpengaruh langsung akibat kadar kekeruhan yang tinggi adalah kandungan oksigen terlarut. Diliana (2014) menyatakan bahwa kekeruhan yang tinggi pada perairan dapat menyebabkan kandungan oksigen menurun. Hal ini disebabkan intensitas cahaya matahari yang masuk kedalam perairan sangat terbatas sehingga tumbuhan / phytoplankton tidak dapat melakukan proses fotosintesis untuk mengasilkan oksigen.

Oksigen terlarut adalah parameter kimia air yang sangat penting di dalam kegiatan akuakultur. Kandungan oksigen yang rendah dapat mengakibatkan kematian ikan dalam jumlah besar. Ikan memerlukan oksigen untuk proses respirasi (bernafas), dan sebagai bahan bakar untuk proses metabolisme. Jumlah oksigen yang diperlukan oleh ikan bergantung kepada beberapa hal, antara lain ukuran tubuh, rasio pemberian pakan, aktivitas, suhu, dll (Effendi, 2003). Ikan yang berukuran kecil lebih membutuhkan oksigen dibandingkan dengan ikan yang berukuran besar yang disebabkan oleh adanya perbedaan aktifitas metabolisme. Ikan yang diberikan pakan lebih banyak membutuhkan kandungan oksigen yang lebih banyak yang akan digunakan dalam proses pencernaan. Ikan yang berenang atau beraktifitas lebih aktif akan membutuhkan oksigen untuk keperluan respirasi. Suhu yang lebih tinggi, cenederung menyebabkan ikan mengkonsumsi oksigen yang lebih banyak dibandingkan dengan kondisi suhu yang rendah.

Optimalisasi pertumbuhan dan produktifitas kolam budidaya ikan bisa didapatkan apabila kandungan oksigen pada airnya tinggi. Menurut Scabra dan Setyowati (2019), kandungan oksigen 
pada media budidaya ikan sekurang-kurangnya adalah $4 \mathrm{mg} / \mathrm{l}$. Pada nilai kandungan $<4 \mathrm{mg} / \mathrm{l}$, ikan dapat mengalami stress, pada kandungan $<2 \mathrm{mg} / \mathrm{l}$ bisa terjadi kematian. Secara tidak langsung, kandungan oksigen yang rendah juga berpengaruh terhadap kehidupan mikroorganisme pada perairan. Dekomposisi (penguraian) bahan-bahan organik (terdir dari algae, bakteria, dan bahan buangan ikan) yang dilakukan oleh mikroorganisme seperti nitribakter, niitrosomonas, dan semacamnya, merupakan proses yang sangat bergantung dengan keberadaan oksigen.

Kegiatan pengabdian kepada masyarakat ini bertujuan untuk meningkatkan produktifitas lahan pembudidaya ikan air tawar di Desa Bayan, Kabupaten Lombok Utara. Usaha peningkatan produktifitas lahan tersebut dapat dilakukan dengan cara melakukan perbaikan kualitas air terutama pada parameter kandungan oksigen terlarut. Maske et, al., (2012) menyatakan bahwa peningkatan kandungan oksigen terlarut pada air dapat dilakukan dengan mengaplikasikan perangkat teknologi Mikro Bubble Generator (MBG). Perangkat MBG adalah suatu alat yang berfungsi untuk menghasilkan gelembung udara di dalam air dengan ukuran diameter kecil serta untuk mengoptimalkan tingkat dan jumlah transfer oksigen. Rosariawari et. al., (2018) menyatakan bahwa perangkat MBG dengan metode spherical ball pada tekanan 13 Psi dapat meningkatkan kandungan oksigen terlarut pada media budidaya ikan hingga mencapai $12 \mathrm{mg} / \mathrm{l}$. Widjaja (2018) telah mengujicobakan teknologi ini dengan hasil yang baik, yaitu terjadinya peningkatan produktifitas budidaya udang vannamei, dari padat tebar supra intensif yaitu 400 ekor/m3 menjadi padat tebar ultra-intensif yaitu 1000 ekor/m3.

\section{METODE KEGIATAN}

\section{Survei lokasi}

Survei awal pada lokasi pelaksanaan kegiatan diperlukan untuk mengetahui kondisi nyata para pembudidaya ikan. Kegiatan survei menjadi hal yang mutlak dilakukan agar kegiatan dapat berlangsung dengan baik, yaitu mencapai nilai efektifitas yang tinggi. Survei awal juga menjadi moment untuk mengenal lebih dekat para pengelola (masyarakat) kolam ikan, dan stakeholder tarkait seperti perangkat desa atau pemerintah daerah pada lokasi tempat pelaksanaan kegiatan.

2. Penyusunan materi sosialisasi

Materi sosialisasi disusun berdasarkan penelaahan pada permasalahan yang terjadi pada masyarakat. Materi yang disampaikan disusun dengan baik, yaitu disesuaikan dalam penyampaiannya agar mudah difahami oleh kelompok masyarakat yang tergolong awam. Pelaksanaan sosialisai direncanakan tidak hanya melibatkan kelompok masyarakat pembudidaya ikan saja, tetapi juga stakeholder terkait seperti perangkat desa dan pemerintah (dinas) terkait.

3. Pembentukan model teknologi

Kegiatan pengabdian kepada masyarakat ini ditargetkan dapat memberikan paket bantuan kepada pembudidaya ikan di Desa Bayan berupa Perangkat teknologi Micro Bubble Generator (MBG). Pembentukan model teknologi didasarkan atas pengalaman tim pelaksana dalam mengelola kolam budidaya ikan yang terstandar. Instalasi paket teknologi tersebut akan dilakukan oleh tim pelaksan kegiatan, sementara operasionalnya akan dikelola oleh mitra.

\section{HASIL DAN PEMBAHASAN}

Materi sosialisai yang disampaikan adalah tentang pemanfaatan tekhnologi mikrobubble dalam hal peningkatan produktifitas lahan perikanan milik warga. Prinsip kerja mikrobubble disampaikan dengan metode yang sederhana agar masyarakat awam dapat memahai dengan baik. 
Mikrobubble merupakan alternatif pengganti penggunaan blower yang dapat memberikan hasil lebih efektif

Micro bubble pada media budidaya ikan dapat dihasilkan dengan beberapa metode dengan karakteristik yang berbeda-beda. Metode tersebut antara lain dengan elektrolityc microbubble generator, porous plate (PP), ventury tube type bubble generator, dan spherical body in a flowing water tube. Perbedaan tersebut dapat dilihat melalui penjelasan pada Gambar 1, 2, dan 3. Pemanfaatan dari teknologi micro bubble ini telah meluas ke berbagai bidang industri. Pada industri perikanan budidaya, alat ini digunakan untuk meningkatkan kandungan oksigen pada tambak atau kolam. Manfaat lain adalah untuk meningkatkan kualitas air sebagai media budidaya ikan.

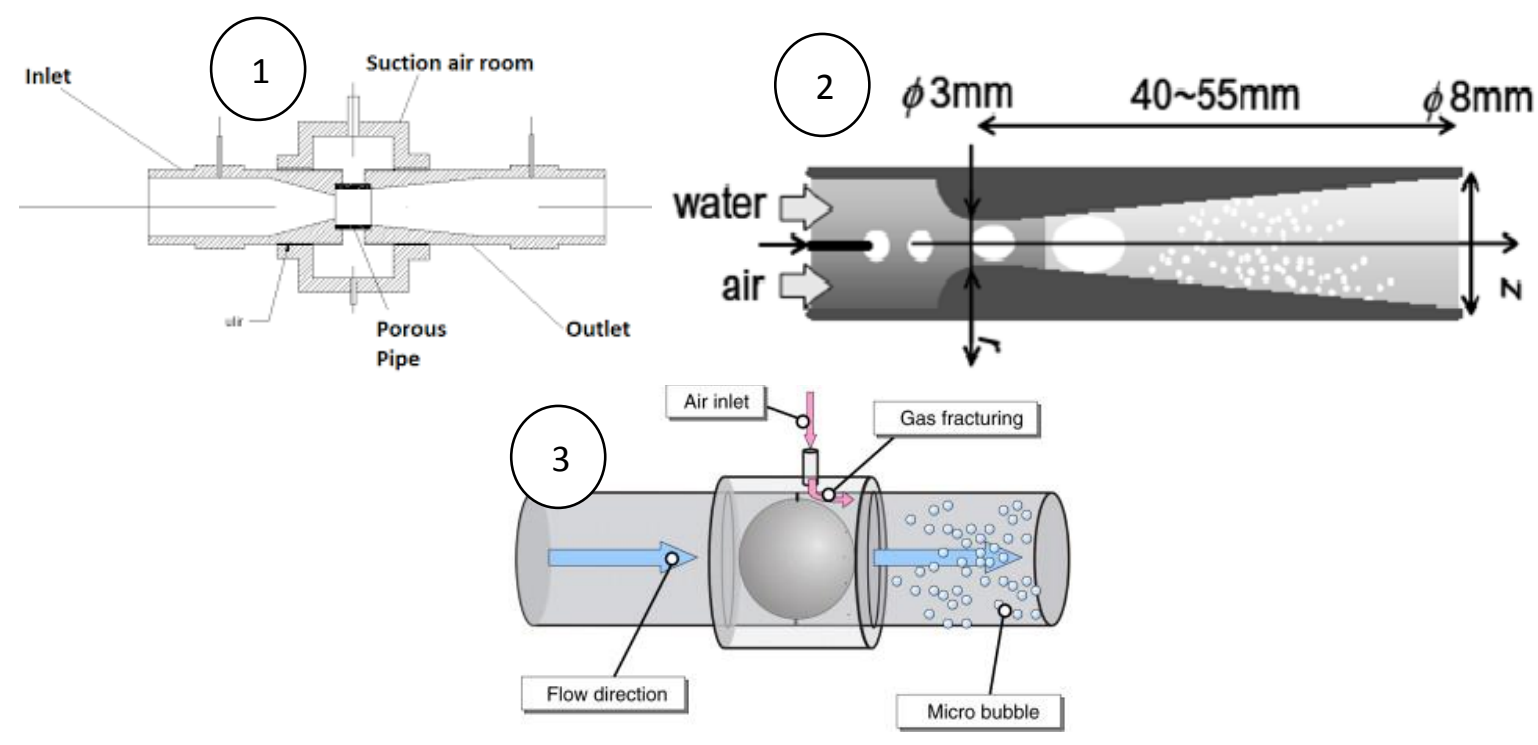

Gambar 1. Microbubble type porous plate (PP); Gambar 2. Microbubble type ventury; Gambar 3. Microbubble type spherical ball

Prinsip Kerja Micro Bubble Generator Metode Spherical Ball adalah menciptakan perbedaan tekanan antara udara luar dengan fluida dalam pipa. Hal tersebut kemudian berdampak terhadap terjadinya titik tekanan vakum pada derah gesekan antara bola dengan pipa. Titik tekan vakum menyebabkan udara (gas) terhisap masuk kedalam aliran fluida melalui lubang-lubang kecil yang telah dipersiapkan.

Apabila suatu aliran fluida bertekanan dialirkan melalui pipa tersebut maka akan terjadi pertambahan kecepatan partikel fluida pada saat melewati daerah sekitar bola, pertambahan kecepatan ini dikarenakan penyempitan penampang saluran oleh bola dan pertambahan panjang lintasan partikel fluida saat menyusuri permukaan bola. Kecepatan tertinggi terjadi pada daerah puncak bola. Berdasarkan persamaan massa dan energy (persamaan Bernoulli), peningkatan kecepatan aliran akan diikuti dengan penurunan tekanan sehingga daerah sekitar puncak bola memiliki tekanan lebih rendah dari pada daerah inlet pipa. Apabila tekanan didalam pipa lebih rendah dibandingkan dengan tekanan atmosfer, maka udara secara otomatis akan terhisap kedalam aliran fluida, melalui lubang-lubang kecil pada Test Section yaitu daerah yang bertekanan rendah. Dikarenakan aliran yang terjadi pada daerah downstream adalah turbulen dan terdapat tegangan geser, udara yang masuk tersebut akan terpecah menjadi micro bubble dengan jumlah yang sangat banyak. 


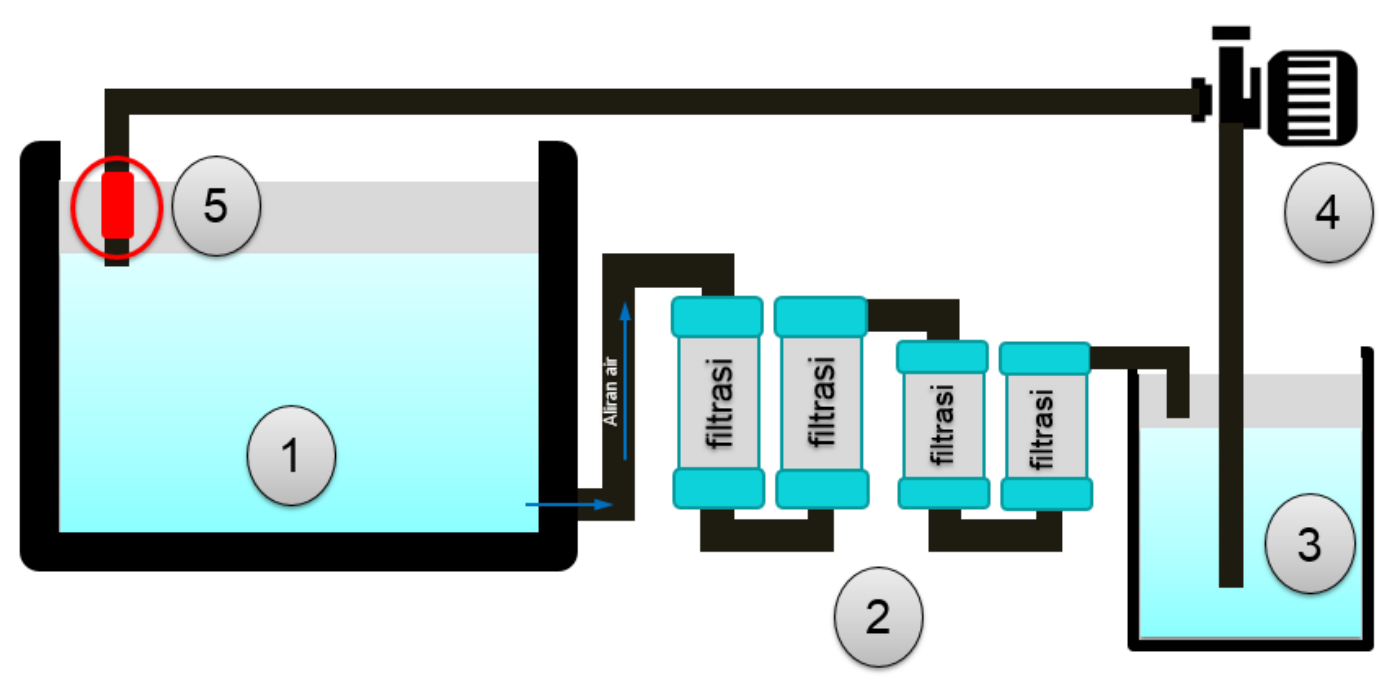

Gambar 4. Instalasi oerangkat Mikrobubble pada sistem budidaya ikan

Perangkat mikrobubble dapat dijelaskan sesuai dengan penomoran pada gambar, sebagai berikut :

1. Gambar nomor 1 merupakan wadah utama tempat pemeliharaan ikan. Pada wadah ini, terjadi aktiftas budidaya ikan yang menyebabkan air media menjadi keruh. Kekeruhan tersebut terjadi akibat pemberian pakan kepada ikan yang dibudidaya. Untuk mengantisipasi agar nilai kekeruhan media budidaya tidak terlalau tinggi, maka perlu dipehatikan berbagai faktor, antara lain kepadatan ikan yang dipeliharan, jenis dan metode pemberian pakan, serta manajemen pengelolaan produksi. Padat tebar ikan yang tidak ideal berkaitan dengan jumlah pakan yang diberikan. Apabila pada wadah pemeliharaan berisa ikan yang terlalau banyak, maka perhitungan pakan juga dapamenjadi terlalau banyak, sehingga berpotensi melebihi carrying capasity dari wadah budidaya. Pakan yang tidak baik juga dapat menyebabkan nilai kecernaan menjadi rendah sehingga melalui sistem sekresi, kualitas air pada media pemeliharaan ikan berpotensi menjadi rusak.

2. Gambar nomor 2 merupakan instalasi filtrasi yang berfungsi dalam menyaring air kotor hasil kegiatan budidaya ikan. Filter tersebut terdiri dari filter fisik, kimia dan biologis. Bagian awal filtrasi diawali dengan filter fisik, kemudian diikuti dengan kimia, dan terakhir filter biologi. Filter fisik terdiri dari kapas sintetis dan kertas dakron. Melalaui filter tersebut, kualitas air yang diharapkan terfilter adalah bagian terlarut pada air yang terdiri dari kotoran ikan dan sisa remahan pakan yang tidak termakan. Filter kimia terdiri dari batu zeolit dan karang jahe. Melalaui filter ini, bagian parameter kualitas air yang diharapkan dapat tersaring adalah amonia, nitrat dan nitrit.

3. Gambar nomor 3 merupakan wadah penampungan media budidaya yang telah terfilter. Media tersebut kemudian akan dialirkan oleh pompa yang terhubung dengan pipa. Wadah penampung media ini enjadi idikator keberhasilan proses filtrasi yang dilakukan. Apabila media yang tertampung pada wadah ini memiliki kualitas yang lebih baik secara fisik, kimia, dan biologi dibandingkan dengan media yang tertampung pada wadah utama, maka filtrasi dpaat dikatakan berhasil.

4. Pompa akan mengalirkan air pada wadah tandon menuju wadah utama tempat pemeliharaan ikan. Penggunaan pompa menjadi sangat vital karena fungsinya yang tidak hanya berkatan 
dengan mikrobubble, tetapi juga dengan sistem filtrasi yang dijalankan. Semkain bagus kualitas pompa yang digunkana, mak akan semakin awet sistem pemeliharaan ikan yang berjalan.

5. Gambar nomor 5 merupakan perangkat mikrobubble yang terdiri dari tiga type mikrobubble sebagaimana yang telah dijelaskan. Dari ketiga type yang ada, perangkat mikrobuble yang dibuat adalah mikrobubble bertype ventury. Pemilihan type mikrobubble yang digunakan didasarkan pada kemudahan dalam hal pengadaan peralatan yang dibutuhkan.

Model tekhnologi mikrobubble

Pembuatan paket tekhnologi mikrobubble dilakukan dengan menggunakan bahan-bahan berupa pipa yang memiliki ukuran yang telah diatur, yaitu 1 inch, dan $3 / 4$ inch. Pipa tersebut dipotong dan dirakit sesuai dengan fungsi masing-masing. Penggunaan ukuran pipa tersebut disesuaikan dengan kekuatan pompa yang digunakan. Apabila pompa yang digunakan memiliki tegangan kekuatan yang besar, maka ukuran pipa yang direkomendasikan juga sebaiknya menyesuaikan. Pada kegiatan yang dilakukan, pompa yang digunakan adalah popa dengan daya 300 watt. Pompa air dan Perangkat mikrobubble yang dirakit melalui kegitan ini dapat dilihat pada Gambar 5 dan 6 .
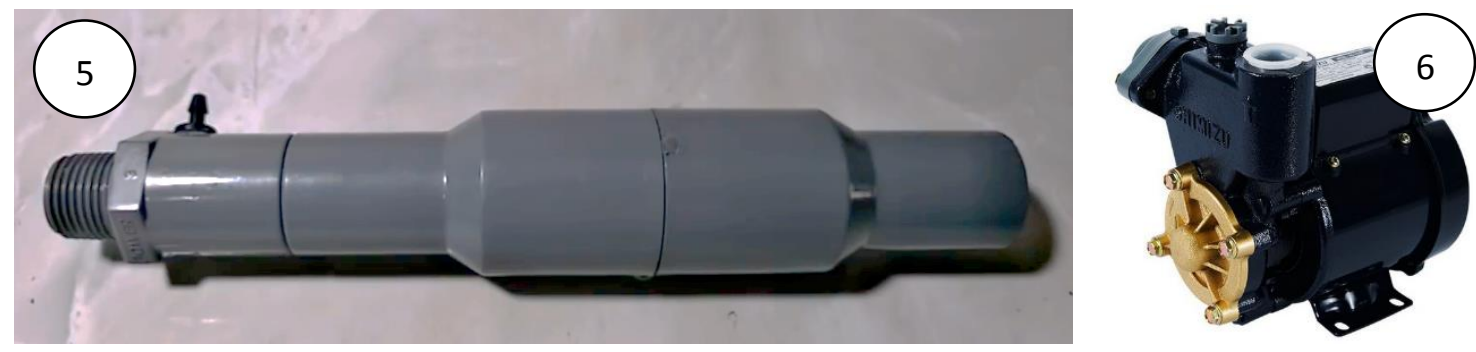

Gambar 5. Design modifikasi pipa yang terkoneksi dengan pompa air; Gambar 6. Jenis pompa air yang dugunakan untuk menghasilkan mikrobubble

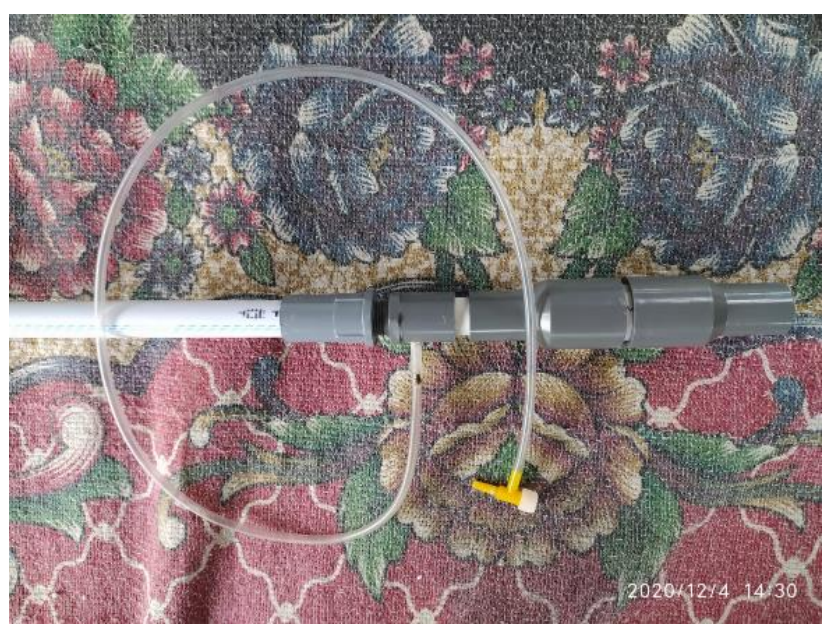

Gambar 7. Sistem pengeluaran air yang terkoneksi dengan selang udara 
Pada Gambar 7, terlihat penampang model ujung pengeluaran air yang terkoneksi dengan selang udara. Perbedaan ukuran pipa yang telah diatur sedemikian rupa menyebabkan adanya perbedaan tekanan air di dalam pipa. Hal tersebut menyebabkan udara luar yang terhubung melalui selang kecil akan tersedot masuk ke dalam aliran pompa. Selanjutnya, pada bagian dlaam pompa, telah ditanamkan pemecaha air berupa ventury tube yang menyebabkan udara yang masuk ke dalam aliran pompa menjadi terpecah hingga dapat memunculkan butiran-butiran yang lebih kecil. Pad aGambar 8, diperlihatkan penyerahan bantuan berupa pompa, model mikrobubble, dan keperluankeperluan lainnya.

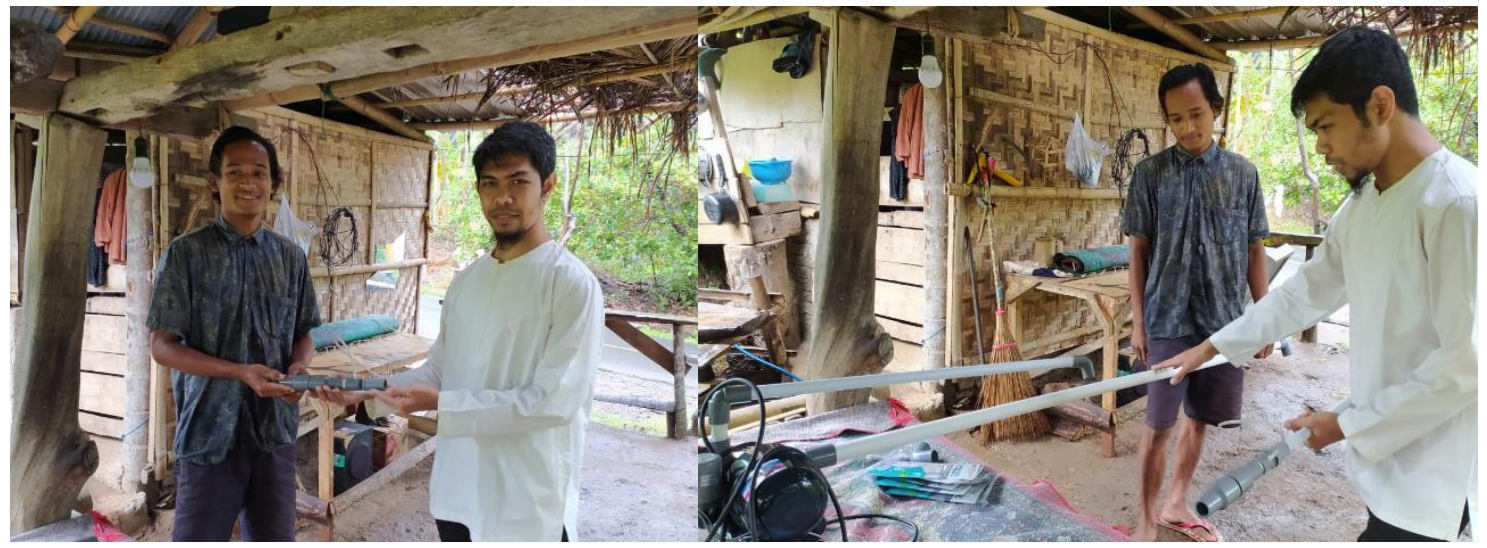

Gambar 8. Penyerahan bantuan peralatan kepada mitra terlibat

KESIMPULAN DAN SARAN

\section{Kesimpulan}

Melalui kegiatan ini, masyarakat menjadi lebih paham tentang penitngnya sertifikasi CBIB dan metode/tekhnologi perbaikan kualitas air terutama pada indikator oksigen terlarut. Dengan pemahaman tersebut, produktifitas lahan kolam budidaya ikan diharapkan dapat mengalami peningkatan.

\section{Saran}

Beberapa poin yang menjadi saran dalam pelaksanaan kegiatan ini adalah:

1. Diperlukan duplikasi kegiatan yang dilakukan pada kelompok-kelompok lain

2. Perlu pemahaman yang lebih lanjut mengenai perbaikan kualitas air selain dari indikator oksigen terlarut.

3. Kegiatan pengabdian diperlukan dalam jangka waktu yang lebih panjang sehingga kontribusi yang diberikan kepada masyarakat lebih terasa. 


\section{UCAPAN TERIMAKASIH}

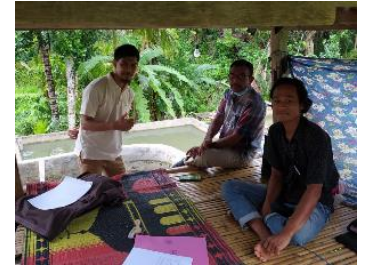

Terimakasih diucapkan kepada Lembaga Penelitian dan Pengabdian Universitas Mataram yang telah memberikan bantuan pendanaan melalui skema Pengabdian Kemitraan PNBP Unram Tahun Anggaran 2020. Terimakasih juga disampaikan kepada kelompok petani ikan "brothers bikuq" yang telah menjadi mitra dalam kegiatan ini.

\section{DAFTAR PUSTAKA}

Anonimous. 2014. Profil Potensi Desa Bayan Kabupaten Lombok Utara. https://bayanlombokutara.desa.id/first/artikel/59.

Boyd CE. 1982. Water Quality Management in Pond Fish Culture. New York (US): Elsevier Scientific Publishing Company.

Diliana, SY. 2014. Limnology: Pengaruh Kekeruhan / Turbidity terhadap Ekosistem Perairan. Jatinangor (ID): Universitas Padjajaran.

Effendi H. 2003. Telaah Kualitas Air bagi Pengelolaan Sumberdaya dan Lingkungan Perairan. Yogyakarta (ID): Kanisius.

Rosariawari, F., Wahjudijanto I., Rachmanto, TA. 2018. Peningkatan Effektifitas Aerasi Dengan Menggunakan Micro Bubble Generator (MBG). Jurnal Ilmiah Teknik Lingkungan, 8 (2) : 88-97.

Maske, SJ., Rai, DS., Kale, VS., Raut, BD., Chintale, GA. 2012. Microbubble and its applications. International journal of pharmacy \& life sciences, 3 (12): 2228-2235.

Sadatomi, M., Kawahara, A., Kano, K., Ohtomo, A. 2005. Performance of a New Micro Bubble Generator with a Spherical Body in a Flowing Water Tube. Science direct : Experimental Thermal and Fluid Science, 29 (5) : 615-623. https://doi.org/10.1016/j.expthermflusci.2004.08.006

Scabra AS, Setyowati DN. 2016. Peningkatan Mutu Kualitas Air Untuk Pembudidaya Ikan Air Tawar Di Desa Gegerung Kabupaten Lombok Barat. Abdi Insani, 6 (2) : 261-269.

Widjaja, S. 2018. BRSDM Ciptakan Teknologi Microbubble untuk Budidaya Udang Vaname Ultra Intensif. https://kkp.go.id/brsdm/artikel/8233-brsdm-ciptakan-teknologi-microbubbleuntuk-budidaya-udang-vaname-ultra-intensif. 